\title{
Spousal and parental roles among female student populations in 55 low- and middle- income countries ${ }^{1}$
}

\author{
Albert Esteve, Jeroen Spijker, Tim Riffe and Joan García*
}

\begin{abstract}
This paper exploits a vast database of international census and survey microdata to examine the relationship between school enrolment on the one hand and the status of being in a union or a parent on the other among female adolescents and young adults in low- and middle-income countries. Our analysis is based on widespread evidence for 55 countries among 15 to 24 year-old females. High shares of student population are strongly correlated with low shares in spousal and parental roles between countries. We show that this relationship is driven by the fact that students are less likely to be in spousal and parental roles compared to non-students. Nevertheless, as we compare older ages, the share of students reported as spouses and/or mothers increases. The prevalence of spousal and parental roles among the student population is correlated to the overall levels of spouses and mothers in the total population, even when controlling for the level of school currently attained.
\end{abstract}

\section{Introduction}

Individuals that stay in school longer usually form relationships and have children later than those who leave school at younger ages. Between countries, the proportion of adolescents and young adults living in marital or non-marital cohabitation and raising children tends to be lower where a large proportion goes to school. The mechanisms through which time spent in school exerts an influence on age at marriage and childbearing are diverse. Some of these mechanisms operate at ages after schooling has been completed, while others only operate within typical school ages (Thornton et al. 1995). An instance of the latter

\footnotetext{
1 Support for this research comes from the WorldFam project (ERC-2009-StG-240978).

* Albert Esteve (correspondence author), Center for Demographic Studies, Barcelona, Edifici E2, Centre d'Estudis Demogràfics, Bellaterra, 08193, Spain. Email: aesteve@ced.uab.es Jeroen Spijker, Tim Riffe and Joan García, Center for Demographic Studies, Barcelona.
} 
kind of mechanism is role incompatibility, referring to the difficulty of being a spouse or a parent while also being enrolled in school. Students are in school almost continuously from the age of six until the early twenties if primary, secondary and undergraduate levels are completed. Education systems are almost universally organised into the familiar three-stage scheme of primary, secondary and tertiary levels but school enrolment rates vary greatly between countries. By the year 2000, more than $95 \%$ of 16 year-old females were enrolled in school in the United States and France, but these figures were much lower in Brazil (78.7\%), Cambodia (37.0\%) and Niger (10.1\%). Less than two percent of 16 year-old women in the United States and France were in union, whereas more women were in union in Brazil (9.7\%), Cambodia (4.4\%) and Niger (47.6\%) (https://international.ipums.org/; see data section). The extent to which high levels of school enrolment are associated with low levels of marriage and childbearing during school ages and how this association can be explained by differences between student and non-student populations are the subjects of this paper.

We examine the relationship between school enrolment and spouse and parent statuses of female adolescents and young adults aged 15-24 across 55 low- to middle-income countries around the year 2000 . We focus on low- and middleincome countries because, compared to high-income countries, they tend to have less universal and institutionalised educational systems, lower enrolment rates and earlier marriage and childbearing schedules. These conditions allow a better observation of the relationship between school enrolment and union formation and childbearing.

First, we investigate the association between levels of school enrolment (i.e. student status) and the proportion of males and females in union (i.e. spouses) and females with children of their own (i.e. parents). Second, we examine the degree of dissociation between family roles and schooling. We compare both the proportion in union and the proportion with children between females enrolled in school versus those not enrolled. Are female students in these countries less likely to be in union or have children than those that have completed or exited school, and how does this pattern vary by age? Third, we examine if there are significant differences between countries in the prevalence of spousal and parental roles among student populations. Do countries with early marriage and childbearing display higher marriage and childbearing rates among students?

Our approach is based on declared or inferred statuses of student, spouse (married or cohabiting) or parent. Data came from the international Integrated Public Use Microdata Series database (IPUMS) and from the Demographic Health Surveys (DHS). We use census and survey microdata to build aggregated indicators and examine bivariate relationships at the macro level. 


\section{Background}

The determinants of societal changes in family organisation are still cause for discussion among scholars (Smith 1993; Thornton 2005). Despite different views on what drives family change, the effect of education is commonly agreed upon. Education conveys both structural and ideational influences on family life (Jayakody et al. 2008; Skirbekk 2008; Lutz 2010; and see Buchmann and Hannum 2001 and Hannum and Buchmann 2004 for a review of the literature). Education delays age at first union and first birth (Bongaarts 2003; Castro Martín 1995; Kravdal 2002; Mensch et al. 2005). The main demographic transitions to adulthood thus tend to occur after school has been completed as most young adults, males and females, are assumed to enter into their first unions (marriage or cohabitation) and have their first child outside of school. Regardless of whether school is left in order to marry or to have a child, or whether these transitions occur independently once schooling is completed, there appears to be what one could call an incompatibility of roles, which prevents most people from being both in school and fulfilling spousal and parental obligations.

This role incompatibility is potentially due to three interrelated factors: a lack of economic and personal independence while in school, exclusive time use, and parental control (Lloyd 2005). First, the decision to marry and have children implies a certain degree of economic stability, at least for one of the spouses involved. Students often do not earn money and those that do generally do not earn enough to live independently with a spouse. Second, irrespective of educational level, schools are generally highly controlled and demanding environments that require exclusive dedication of time spent on school premises, in transit to and from school, and possibly also on doing school-related homework. Marriage and childbearing implies spending time with one's spouse and child(ren) as well as spending time with work, either to secure income or to carry out domestic chores. Finally, this sheltered time use is often demanded and provided for by parents, who view their children's education as an investment. Parents may view their own children as a form of old-age security, the value of which increases with the level of children's education. Likewise, they may see union formation and childbearing as barriers, preventing their children from satisfactorily finishing their studies, and so they may discourage family transitions until schooling has been completed.

This research does not attempt to separate and verify the underlying mechanisms that generate role incompatibility, but rather strives to examine differences between students and non-students in family role statuses. We expect that because of role incompatibility female students will be significantly less engaged in spousal and parental roles than those not enrolled in school and, therefore, in societies with higher school enrolment levels, the proportion of females in spousal and parental roles will be lower. However, our analysis does not set out to examine the underlying mechanisms generating this role 
incompatibility in each country. It is also important to mention that we do not expect all countries with low enrolment rates to display high proportions in union or with children just because a large share of the population has left school.

School enrolment versus union and parental status: age and sex patterns

As individuals age through their teens, interests in schooling, relationships and childbearing begin to overlap. Even in countries where marital transitions occur very early (for instance western Africa and in certain regions of India), only rarely do interests in schooling and marriage collide before age 12 (Lloyd 2005). Conflicts between schooling and partner formation are rare or non-existent until at least the mid-teens. Primary schooling, which usually stops around age 12, should therefore be free of interference from partnering and childbearing. However, from age 12 onwards, especially among women in early marriage cultures, women may start to marry and have children which may bring about conflicts between schooling and partnering. The extent to which adolescents and young adults in school will be able to engage in partnership or have children would be conditioned by two main and, somehow, opposite forces. On one hand, schooling itself becomes more demanding at each increasing level. On the other, young people are subject to increasing social pressure to marry because an increasing number of people of the same age are doing so. While such pressures may be responsible for removing young women and men from secondary and tertiary school, we also expect a greater prevalence of spousal and parental roles among students with increasing age.

Males and females are subject to different constraints limiting the ability to reconcile marital and student life. Transitions to marriage and childbearing occur earlier in life for women than for men and enrolment rates differ greatly between the sexes in many countries. Marriageability for men is usually tied to the ability to secure economic independence sufficient to support a family, whereas this condition does not always apply to women, especially in male-breadwinner family systems. Males usually go to school more universally and for a longer time, although the gender gap has narrowed in recent decades, and in a select few countries has even reversed (Esteve et al. 2011). The relationship between school enrolment and being in a union or a parent is stronger for women than for men, since in many societies women start unions and begin having children during typical, or potential, school ages. Therefore, our analysis is restricted to women.

\section{Data and methodology}

Sources and countries selected

For our analysis we combine data from (i) the Integrated Public Use of Microdata Series (IPUMS) International database (Minnesota Population Center 2011), the most complete database of global census microdata available today ( 62 countries, 
185 censuses, 397 million individual records for the period 1960-2008); and (ii) the Demographic and Health Surveys (DHS) (ICF Macro 2011), a survey that has collected, analysed and disseminated accurate and representative data on population, health, HIV and nutrition from more than 260 surveys over 90 countries. Only countries whose census or survey data identify students, spouses and parents in the age range 12 to 24 by single ages were selected. This left us with samples from 55 countries (28 from Africa, 10 from Asia and 17 from Latin America), totalling almost 18 million cases (see Appendix 2). 31 samples were from the IPUMS database and 24 from the DHS Surveys. All samples were around the year 2000 and only one dataset was selected for each country. In case both IPUMS and DHS data were available for one country, the IPUMS data were preferred because of the larger sample sizes.

The analysis is based on the population aged 12-24. Students are identified from age 12 to 24 but spouses and parents only from age 15 onwards. For each sample, proportions of each variable were aggregated by single ages. Resulting age curves that presented extreme volatility or implausible shifts, often due to age heaping on age 20 and/or low sample sizes, were adjusted using a smoothing spline. This procedure affected roughly one-quarter of the series, mostly crosstabulated DHS data, and in no series did the smoothing produce undesired side effects.

\section{Students}

In IPUMS datasets, students were identified on the basis of 'school enrolment' (SCHOOL) and, lacking this variable, by 'activity status' (EMPSTAT). Most census questionnaires contain a direct question on school enrolment, while some censuses include the option to answer 'in school' in the question on employment status. For DHS data, the dichotomous variable was created on the basis of the variable 'still in school' (HV110). Individuals with student status were assumed to be enrolled, but neither is there any information on education levels attained nor whether the person has stayed continuously in school. When available (50 countries), we therefore used the 'educational attainment' variable from the census data and 'highest educational level' from the DHS to establish the level until which a person was enrolled, but which they did not necessarily complete. One reason to distinguish education levels for students is because census data do not indicate when people leave school. For instance, a 20 year-old mother enrolled in primary school is likely to have spent a number of years outside of the schooling system (see Appendix 1).

\section{Spouses}

In IPUMS data, spouses were identified on the basis of 'marital status' (MARST) and 'spouse's location in the household' (SPLOC). Any person who responded 'married/in union' and/or had an identifiable spouse in the household was considered a spouse. We included both married and non-married couples as well as those who did not specifically declare themselves as 'cohabiting' or 'married' 
but stated their relationship to the household head as 'spouse'. For the DHS data the information was obtained directly from the 'marital status' variable (H502 for the female respondents and HV116 for the general population).

Parents

Parental status information is typically only available for women. Many DHS surveys do not include male questionnaires, and most censuses do not provide information on children for men. Using census data, there were two options to identify the parental status of individuals: 'children ever born' (CHBORN) or the 'number of children in the household' (NCHILD). The latter is a variable created by IPUMS on the basis of relationships between household members. First, the variable CHBORN was used to identify parent status for all samples that included this variable. For individuals with a missing value for CHBORN, information was taken from the NCHILD variable. Likewise, for samples lacking the variable CHBORN, the NCHILD variable was used exclusively. In DHS data, information on parental status was drawn from the variable 'children ever born' (V201).

Before showing the results of the main analysis, a few stylised facts are provided on the country-specific characteristics of educational enrolment, spousal and parental status (see also Appendix 2):

- Enrolment among 12-24 year-old females is highest in central Asia and the Caribbean except Haiti (60\% on average) and lowest in Africa (e.g. 10\% among women in Benin) except for Gabon, South Africa, Namibia and Congo where between $55 \%$ and $65 \%$ of females in this age group go to school.

- The proportion of 15-24 year-old women in union ranges from $12 \%$ in South Africa to $67 \%$ in Niger. Levels are highest in western and middle Africa and lowest in western, eastern and south-eastern Asia.

- The proportion of 15-24 year-old women who are mothers ranges from $12 \%$ in the Philippines to $58 \%$ in Mozambique. The highest proportions are found in Africa except Morocco and the lowest in Asia (19\% on average with few regional differences). Although one may expect the proportion of females who are mothers to be lower than the proportion in union, this is not necessarily the case (see e.g. Jamaica).

\section{Results}

The relationship between school enrolment and union formation and childbearing

Figures $1 \mathrm{a}$ and $1 \mathrm{~b}$ are composed of a series of boxplots summarising the betweencountry distribution of population aggregate percentages of students, spouses and parents over single ages from age 15 to 24 (12 to 24 for school enrolment) near the year 2000 for 55 countries. As an exception, we include data for males to illustrate the small overlap in roles compared to females. 
School enrolment levels decrease by age for both males and females, and are on average higher among males than among females. Between-country variability in enrolment is highest at ages 15-18, which corresponds with between-country variation in the end of compulsory schooling. Figure 1a shows that both proportions in overall levels of enrolment and inter-country differences begin to decrease after age 17. Variation among males follows the same pattern, but at a slightly lower level than that observed for females. Regarding family roles, the percentage of males and females in union and females with children increases with age. Among females, the proportions of spouses and of mothers are relatively low at age 15 , but start to increase sharply after age 18 . Regarding the proportion of spouses, half of the countries analysed have values over $27 \%$ by age 18 , reaching $66 \%$ by age 24 . A similar trend is shown for males, although fewer males are in spousal roles at the same age ( $4 \%$ at age $18,31 \%$ at age 24$)$. The age pattern of mother status closely follows that observed for unions, although there is a cross-over around the age of 19-20, after which more females are mothers than spouses. We suspect that this reflects the presence of single mothers, break-ups and excess male mortality. For instance, when analysing the country-specific results we can already see that at age 20 the difference in the percentage of females in union with those who are already mothers is $-29 \%$ in the case of Jamaica and $-27 \%$ in South Africa, while the 55 -country median is $0.6 \%$.

\section{Figure 1:}

Age-specific between-country variability in percentages student, spouse and mother a female b males
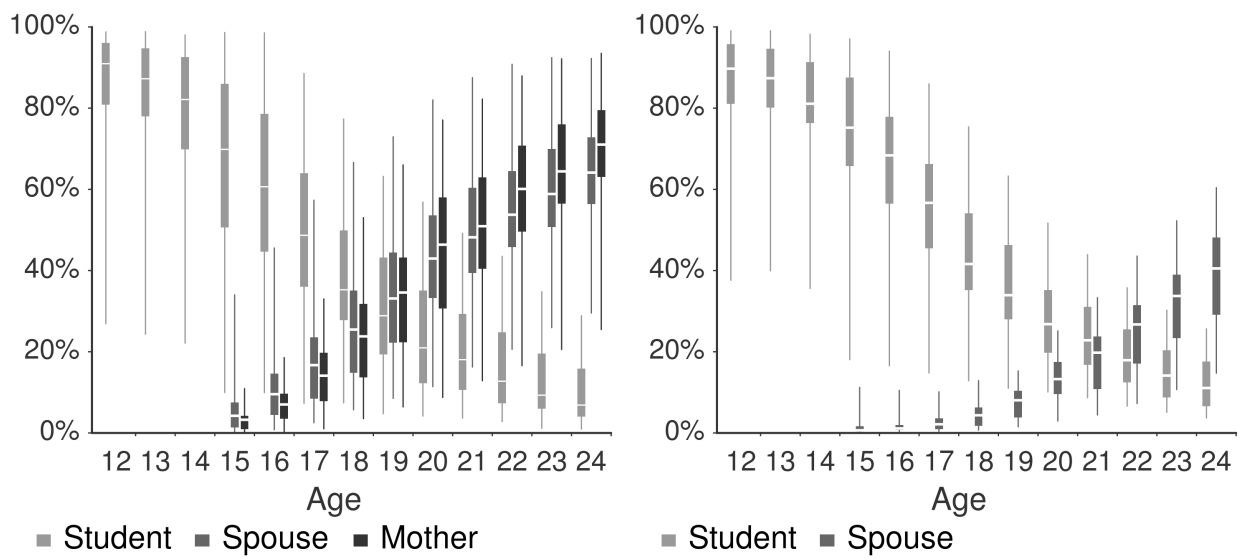

Source: IPUMS and DHS. See Table A.1 for the countries in each figure.

Figure 2 shows the bivariate relationship between the aggregate percentage in school on the $\mathrm{y}$-axis and percentage in union on the $\mathrm{x}$-axis separately for every other age from age 16 to 24 . For visual reference, a line has been fit to the points from each age separately using Deming regression (Deming 1943), a bivariate 
subset of Total Least Squares regression. We assign equal weight to $\mathrm{x}$ and $\mathrm{y}$ residuals in optimising the fit, thus errors are perpendicular to the fitted line, rather than only with respect to $y$. This yields no radical benefit, except that one will always come to the same conclusions if $\mathrm{x}$ and $\mathrm{y}$ are swapped in the regression. Confidence bands are also displayed at the 95\% level. Since no analytical formula was on hand for these, they were derived by bootstrapping; we resampled rows from the data with equal probabilities and replacement up to the original sample size a total of 1000 times for each fitted line. The Deming line was refit to each sample. The $95 \%$ confidence bands are approximated as the 0.025 and 0.975 quantiles from the 1000 fits. Both the fitting and the bootstrapping were done using the Deming function of the MethComp package (Carstensen et al. 2012) in R ( $\mathrm{R}$ Core Team 2012). All fits in the following scatterplots used this same methodology.

For females the negative relationship between the proportion enrolled and being a spouse is strong, significant and consistently increases in magnitude as age increases. The age-specific linear fits in Figure 2 show that proportions in school of the general population are a strong and significant predictor of proportions in union at all ages, and vice versa, but that the nature of the relationship changes over age. To illustrate this, around age 18 a country with $10 \%$ higher percentage of females enrolled in school on average has around $8 \%$ lower percentage of females in union. By age 22 this relationship increases in magnitude to $+10 \%$ predicting $-19 \%$, respectively.

Figure 2:

Age-specific bivariate relationship between percentage in union and percentage enrolled

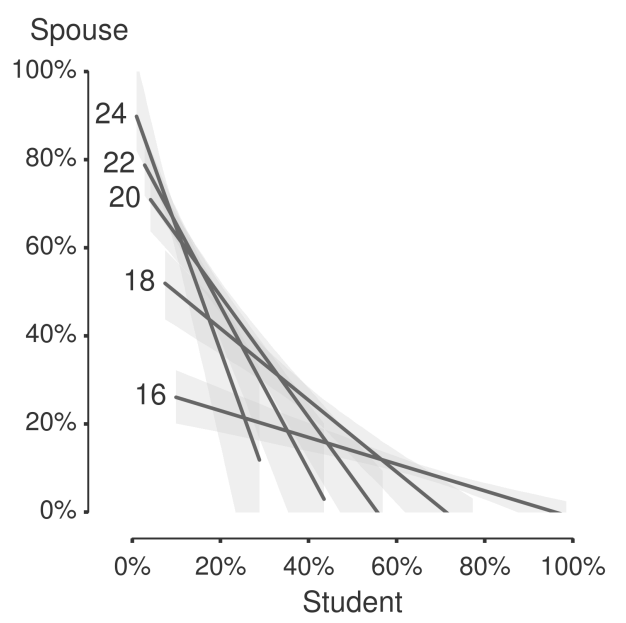

Source: IPUMS and DHS. See Table A.1 for countries included 
Figure 3 is identical to Figure 2 except that the proportion spouses has been switched to be the proportion of females that are mothers. As is the case with Figure 2, the age-specific relationships between school enrolment and motherhood are strong and significant. The magnitude of the relationship follows a similar decreasing pattern over age. A similar negative relationship as was seen for union status between ages 18 to 20 is also seen for motherhood, although before that age the slope is much lower, while after the age of 20 the slope becomes substantially higher. For example, at age 24 a $10 \%$ higher enrolment predicts $43 \%$ lower motherhood compared to $28 \%$ fewer in-union women. In other words, among young adults being enrolled in (tertiary) educational institutions discourages having children more than it discourages entering in union, while among adolescents it is the other way around.

\section{Figure 3: \\ Age-specific bivariate relationship between percentage mother and percentage enrolled}

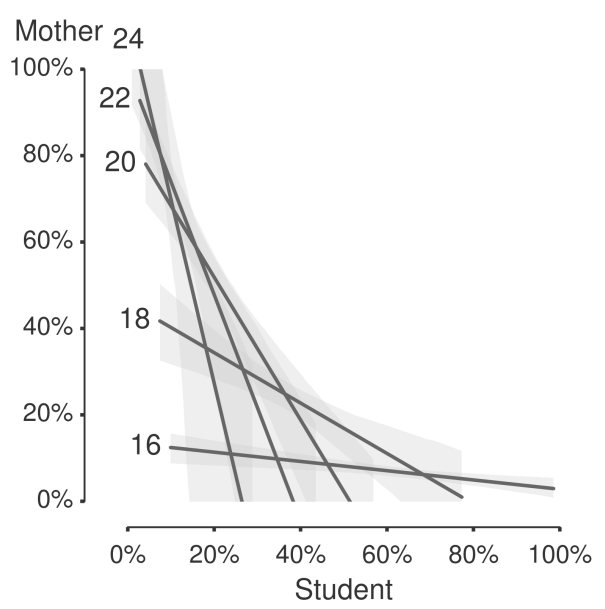

Source: IPUMS and DHS. See Table A.1 for countries included.

\section{Differences by school enrolment status}

We now proceed to compare in-school and out-of-school populations to gain further insight into the strong negative relationships between school enrolment and family statuses shown above in the aggregate. Figure 4 uses boxplots to summarise the age-specific between-country variation in the percentages in union and mother, split by school enrolment for females. We note that the proportion of women in union and with children increases with age irrespective of school enrolment status, and that it is at all ages higher among women not in school than those enrolled. The prevalence of spousal and parental roles among the population going to school increases with age. By age 20 the median percentage of women who are mothers or in union outside of school among the countries studied was 
about $50 \%$, whereas for enrolled women it was just $10 \%$. At age 24 , in $75 \%$ of all countries the proportion of enrolled women who have family roles is less than about $40 \%$. The observed differences between the enrolled and not enrolled groups are lowest at early ages because the overall levels of in union are lower as well. Not surprisingly, the between-country variation in the proportion of enrolled women in family roles also increases with age, but it is far lower than those not enrolled until around age 22 .

\section{Figure 4:}

Age-specific between-country variability in percentages union and mother by school enrolment status

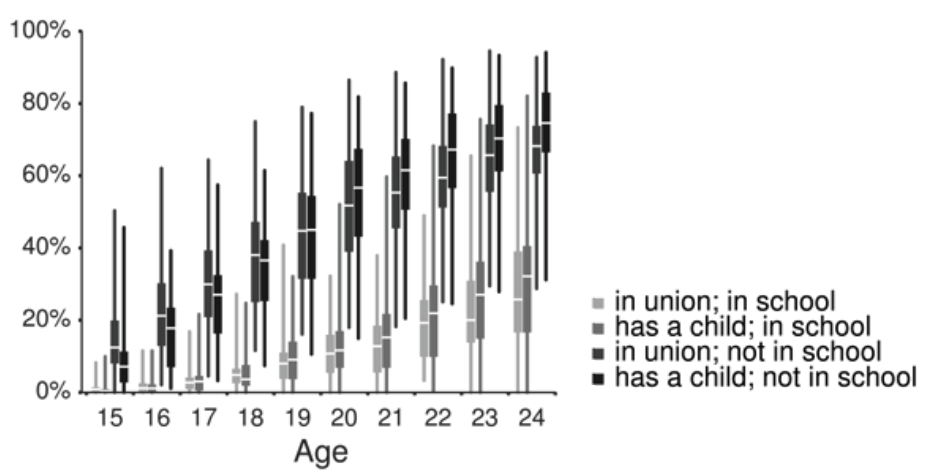

Source: IPUMS and DHS. See Table A.1 for countries included.

Figure 5 shows the bivariate relationship between the aggregate percentage of females who are mothers on the $\mathrm{x}$-axis and percentage of females in school who are mothers on the y-axis separately for every other age from 16 to 24, with linear fits and 95\% confidence regions for each age, as with Figures 2 and 3. The figure shows a strong and significant relationship within each age, and a consistent pattern of relationship increasing over age. There is a strong association between the overall proportion of females who are mothers and the tendency for females in school to also have this role. There is a less than 1:1 relationship at all ages prior to age 24 , for instance at age 16 , a country having $10 \%$ higher percentage females who are mothers predicts $2.6 \%$ higher proportion of students as mothers, increasing to a $4.3 \%$ change by age 20 and $17 \%$ by age 24 . This result means that the percentage of female students with parental roles is sensitive to societal prevalence of childbearing, and this relationship increases with age.

Similarly, Figure 6 shows the relationship between the aggregate percentage of females in union on the y-axis and percentage of females enrolled in school who are in union on the $\mathrm{x}$-axis separately for single ages from age 15 to 24 . The overall age pattern and slopes are very similar to that of in-school and out-ofschool motherhood in Figure 5, although the 95\% confidence bands are wider. Sensitivity is weak at younger ages, and increases with age, albeit not as fast as for motherhood. At age 20 a $10 \%$ increase in the overall percentage of females 
who are spouses predicts a $2.7 \%$ increase in the percentage of female students who are spouses. In almost all cases, family roles in school are lagged considerably behind those outside of school, but they covary strongly. In short, we conclude that what happens outside the in-school population is a strong predictor of family roles among those enrolled in school, but is less strong for union formation than for motherhood.

\section{Figure 5:}

Age-specific bivariate relationship between percentage mother for all females and percentage mother for enrolled females

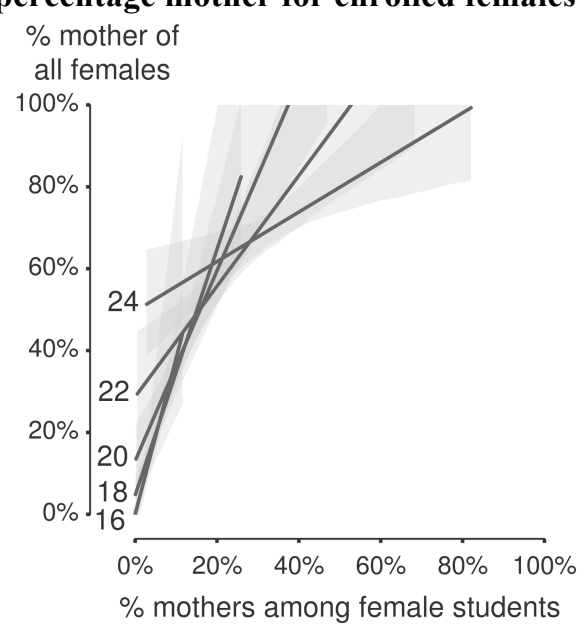

Source: IPUMS and DHS. See Table A.1 for countries included.

Figure 6:

Age-specific bivariate relationship between percentage in union for all females and percentage in union for females enrolled

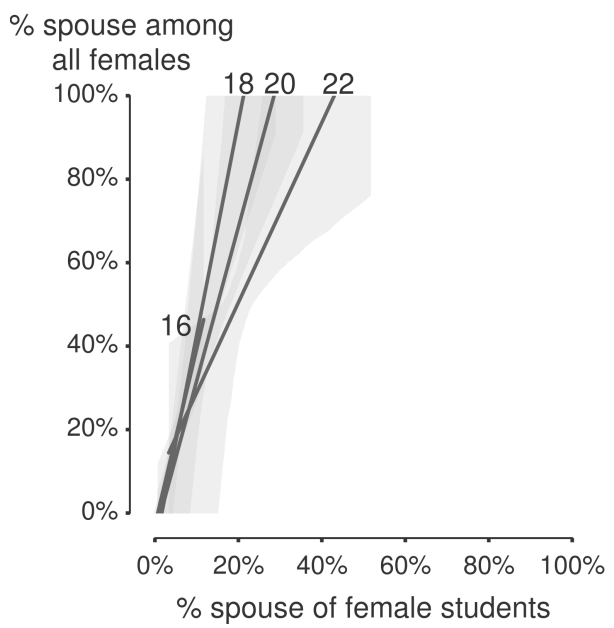

Source: IPUMS and DHS. See Table A.1 for countries included. 
Figure 7 shows the relationship between the aggregate percentage of age 20 females who are mothers on the x-axis and the percentage of age 20 female students who are mothers on the y-axis, split by educational level for those enrolled. In the earlier figures we saw an increasing prevalence of spousal and parental roles among the student population over age. Part of this may be due to the heterogeneity in the grade of school being attended, since in many, especially low-income, countries there are many 20 year-olds who are not university students but are enrolled in lower-level educational programmes (see Appendix 1). In essence, Figure 7 is like Figure 5, except that here we can see that the composition of the enrolled population by educational level is relevant. Furthermore, Figure 7 makes apparent that in some countries there are females enrolled in primary school at age 20 and at the same time show a higher proportion of mothers than the out-of-school population. As expected, females aged 20 years enrolled in at least secondary school level are less sensitive to the overall level of childbearing than those enrolled in primary school but still show a significant association. The relationships within both educational levels are significantly different from one another. ${ }^{2}$

\section{Figure 7:}

Bivariate relationship between percentage mother for all age 20 females and percentage mother for age 20 female students by present level of educational attainment (primary or secondary and more)

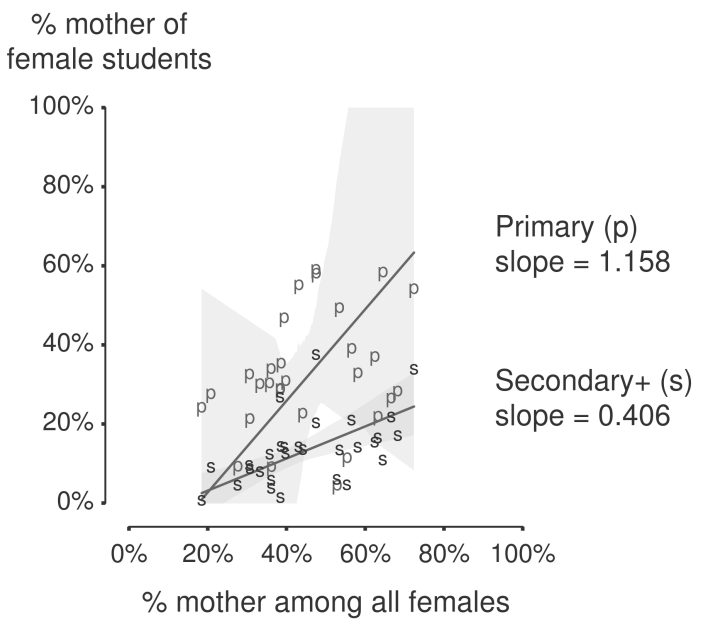

Source: IPUMS and DHS.

Note: University is grouped together with Secondary due to low case counts in many samples. 19 of the countries have been aggregated into $4 \mathrm{UN}$-type macro regions, while 11 countries were excluded due to missing or insufficient data on educational attainment. The figure therefore shows data for 25 individual countries and 4 regions.

2 One can draw the same conclusions for the student population from a Multilevel binary logistic regression model with mother status as the dependent and independent variables for country, age, level of education attained and interactions. Results available from the authors. 


\section{Discussion}

Education is considered to be a major correlate in the timing and quantum of many transitions to adulthood, including demographic events such as entering into a union and childbearing. The mechanisms through which education exerts an influence are diverse and operate differently both in different societal contexts and over age and sex. Using census and Demographic Health Survey data from 55 countries, two main conclusions can be drawn from our results.

First, we have shown that high levels of school enrolment are generally well correlated with low levels of married women and mothers. It is also clear that this relationship is age-dependent. The most direct relation between the level of school enrolment and the proportion in union and mothers is observed at ages 1618. These are typical high-school years, suggesting that increases in school enrolment rates at these ages would yield the largest reduction in the percentage of females married/in union and with children. Before age 16, despite crossnational differences in enrolment rates, no significant association between school enrolment rates and the prevalence of spousal and parental roles has been found.

Second, results indicate that the relationship between overall school enrolment levels and union and motherhood status is mainly due to differences between the in-school and not in-school populations. Female students are systematically less married and have less children than non-students, which is consistent with the idea of role incompatibility. An important result, however, is that spousal and parental levels among female students display a positive and strong relationship with the levels of in union and motherhood in the overall population. This suggests that the presence of an early marriage culture places additional pressure on those enrolled in a school, or that the roles are just more compatible. This relationship also holds after controlling for the level of school enrolment. In other words, women reporting as students in countries where women form unions and have children already at young ages are more likely to be in spousal and parental roles than students in countries with later union formation and childbearing.

Taken together, the two main conclusions may appear contradictory: on one hand, low school enrolment rates are well correlated with high shares of women married and with children in the overall population, in particular when we look at women 16 to 18 years old. On the other hand, high shares of women married and with children are also positively correlated with a high prevalence of spousal and parental roles among the student population, even when controlling for education level attained. One could argue that selectivity into high education is higher when enrolment rates are low. While this may be true, the share of students that will have children is positively correlated to the share of mothers in the whole population, suggesting that a climate favourable to childbearing also influences women still going to school. Further study with better data and tools may shed more light to our findings. 
Some considerations about the quality of the data must be made. The experience of using census and DHS data simultaneously has been positive. The fact that we were using simple indicators made comparisons less problematic. In several countries data were available from both sources for the same or a similar year, and the overall levels were similar when compared (e.g. Cambodia 1998 and Colombia 2005). Despite DHS questions being broader and of better quality than census questions, lower sample densities made the breakdown for ages and educational level attained more difficult, and information on males was usually absent. Basing our analysis on current statuses limited the scope of conclusions to be drawn. A longitudinal approach would have been optimal, i.e. one that tracked the educational and family trajectories of individuals and permitted the differentiation of sequences in transitions. Despite data limitations, the fact that we were able to construct union formation and parenthood indicators for a large number of countries allowed us to investigate the association between school enrolment and union status and childbearing for a large and diverse number of countries, providing an overview of where and for what ages differences in school enrolment are more predictive of marriage/union and childbearing levels.

\section{References}

Bongaarts, J. 2003. "Completing the Fertility Transition in the Developing World: The Role of Educational Differences and Fertility Preferences." Population Studies 57(3): 321-335.

Buchmann, C. and E. Hannum. 2001. "Education and Stratification in Developing Countries: A Review of Theories and Research." Annual Review of Sociology 27: 77102.

Carstensen, Bendix et al. 2012. "MethComp: Functions for analysis of method comparison studies. http://CRAN.R-Project.org/package=MethComp.

Castro Martín, T. 1995. "Women's Education and Fertility: Results from 26 Demographic and Health Surveys." Studies in Family Planning, 26(4), 187-202.

Deming, W. E. 1943 "Statistical Adjustment of Data." New York: Wiley.

Esteve, A., J. García and I. Permanyer. 2011. "Union formation implications of the gender-gap reversal in education: the end of hypergamy." Paper presented at the Population Association of America 2011.

Hannum, E. and C. Buchmann. 2004. "Global Educational Expansion and SocioEconomic Development: An Assessment of Findings from the Social Sciences." World Development 33(3): 333-354.

ICF Macro. 2011. "Measure DHS." Data downloaded from http://www.measuredhs.com.

Jayakody, R., A. Thornton and W. Axinn (eds.). 2008. International Family Change Ideational Perspectives. New York: Lawrence Erlbaum Associates.

Kravdal, O. 2002. "Education and Fertility in Sub-Saharan Africa: Individual and Community Effects." Demography 39(2): 233-250.

Lloyd, C.B. (ed.). 2005. "Growing up Global: The Changing Transitions to Adulthood in Developing Countries". Washington, DC: The National Academies Press. 
Lutz, W. 2010 "Education will be at the heart of the 21 st century demography." Vienna Yearbook of Population Research 2010(8): 9-16.

Melchiorre, A. 2004. "At What Age? ... are school children employed, married and taken to court?" Right to Education Project/ UNESCO-IBE/Swedish International Development Co-operation Agency, Geneva, Switzerland.

Mensch, B.S., S. Singh and J.B. Casterline. 2005. "Trends in the timing of first marriage among men and women in the developing world." Policy Research Division Working Paper 202. New York: Population Council.

Minnesota Population Center. 2011. "Integrated Public Use Microdata Series, International: Version 5.0.” Minneapolis: University of Minnesota.

R Core Team. 2012. "R: A language and environment for statistical computing." $\mathrm{R}$ Foundation for Statistical Computing, Vienna, Austria. http://www.R-Project.org/.

Skirbekk, V. 2008. "Fertility trends by social status." Demographic Research 18: 145180.

Smith, D.S. 1993. "The curious history of theorizing about the history of the western nuclear family." Social Science History 17(3): 325-353.

Thornton, A., W.G. Axinn and J.D. Teachman. 1995. "The influence of school enrollment and accumulation on cohabitation and marriage in early adulthood." American Sociological Review 60: 762-774.

Thornton, A. 2005. Reading History Sideways: The Fallacy and Enduring Impact of the Developmental Paradigm on Family Life. Chicago: University of Chicago Press.

\section{Appendix}

Table A.1:

Percentage of women aged 20 who are enrolled, of mothers and of enrolled mothers according to educational level

\begin{tabular}{llrrrr}
\hline & & \multicolumn{2}{c}{$\begin{array}{c}\text { Unweighted cases } \\
\text { (all ages) }\end{array}$} & \multicolumn{2}{c}{$\begin{array}{c}\text { \% of enrolled women by edu. } \\
\text { enrolled }\end{array}$} \\
Region & mothers & Primary & Secondary + \\
\hline Eastern Africa & Country & 9.4 & 52.0 & 4.3 & 11.3 \\
& Ethiopia & 13.6 & 56.6 & 40.1 & 21.0 \\
& Kenya & 13.3 & 66.6 & 29.4 & 19.4 \\
& Malawi & 12.0 & 27.6 & 8.8 & 4.5 \\
& Rwanda & 5.1 & 62.4 & 38.2 & 15.4 \\
& Tanzania & 16.0 & 72.4 & 55.3 & 33.8 \\
& Uganda & 21.0 & 61.6 & 0.0 & 7.1 \\
Middle Africa & Cameroon & 7.4 & 74.6 & 26.4 & 31.0 \\
& Chad & 30.9 & 60.8 & 43.5 & 22.3 \\
& Congo (Brazzaville) & 2.4 & 75.1 & 0.0 & 8.0 \\
Northern Africa & Niger & 19.1 & 18.5 & 11.2 & 0.7 \\
& Morocco & 21.8 & 46.4 & 0.0 & 13.4 \\
& Lesotho & 7.0 & 68.4 & 0.0 & 0.0 \\
& Madagascar & 13.7 & 77.1 & 60.5 & 29.6 \\
& Mozambique & 26.7 & 45.4 & 0.0 & 18.0 \\
& Namibia & 45.9 & 38.4 & 28.3 & 26.7 \\
& South Africa & 6.8 & 54.0 & No cases & 9.4 \\
\hline
\end{tabular}

(Table A.1 continues on next page) 


\begin{tabular}{|c|c|c|c|c|c|}
\hline \multirow[b]{2}{*}{ Region } & \multirow[b]{2}{*}{ Country } & \multicolumn{2}{|c|}{$\begin{array}{l}\text { Unweighted cases } \\
\text { (all ages) in \% }\end{array}$} & \multicolumn{2}{|c|}{$\begin{array}{l}\text { \% of enrolled women by edu. } \\
\text { level who are mothers }\end{array}$} \\
\hline & & enrolled & mothers & Primary & Secondary + \\
\hline \multirow[t]{11}{*}{ Western Africa } & Benin & 12.5 & 61.2 & 13.6 & 7.7 \\
\hline & Burkina Faso & 4.2 & 72.7 & 0.0 & 18.3 \\
\hline & Côte d'Ivoire & 10.0 & 60.2 & No cases & 9.9 \\
\hline & Gabon & 47.8 & 64.5 & 74.3 & 50.1 \\
\hline & Ghana & 8.5 & 48.1 & No cases & 19.6 \\
\hline & Guinea & 5.0 & 69.5 & 0.0 & 17.2 \\
\hline & Mali & 5.6 & 64.5 & 57.9 & 10.9 \\
\hline & Nigeria & 17.0 & 57.3 & 14.2 & 8.5 \\
\hline & Senegal & 8.0 & 57.0 & 21.1 & 4.3 \\
\hline & Sierra Leone & 14.3 & 55.4 & 13.4 & 5.8 \\
\hline & Togo & 12.3 & 50.8 & 0.0 & 1.6 \\
\hline \multirow[t]{4}{*}{ Caribbean } & Dominican Republic & 51.6 & 47.5 & 72.8 & 20.3 \\
\hline & Haiti & 16.2 & 36.2 & 10.9 & 3.2 \\
\hline & Jamaica & 39.5 & 42.7 & 48.6 & 14.4 \\
\hline & Puerto Rico & 56.9 & 28.2 & No cases & 11.5 \\
\hline Central & & 39.8 & 39.4 & 41.5 & 14.1 \\
\hline \multirow{5}{*}{ America } & Costa Rica & & & & \\
\hline & Guatemala & 12.4 & 56.3 & 89.4 & 12.0 \\
\hline & Honduras & 18.8 & 48.9 & 17.2 & 13.5 \\
\hline & Mexico & 24.2 & 36.1 & 33.5 & 5.8 \\
\hline & Nicaragua & 33.5 & 53.2 & 43.1 & 17.9 \\
\hline Central & Panama & & & & \\
\hline America & & 35.1 & 43.1 & 52.6 & 14.2 \\
\hline \multirow[t]{7}{*}{ South America } & Argentina & 43.1 & 30.6 & 34.6 & 9.5 \\
\hline & Bolivia & 12.0 & 47.5 & 60.1 & 37.5 \\
\hline & Brazil & 35.1 & 35.7 & 29.9 & 12.4 \\
\hline & Colombia & 30.9 & 38.6 & 34.2 & 14.3 \\
\hline & Ecuador & 31.5 & 44.1 & 22.3 & 13.5 \\
\hline & Peru & 38.6 & 33.3 & 25.8 & 8.0 \\
\hline & Venezuela & 39.0 & 39.8 & 32.4 & 12.5 \\
\hline \multirow[t]{2}{*}{ Central Asia } & Kazakhstan & 31.1 & 22.9 & No cases & 18.5 \\
\hline & Kyrgyz Republic & 27.9 & 30.7 & 0.0 & 7.9 \\
\hline Eastern Asia & Mongolia & 31.6 & 25.8 & 0.0 & 8.7 \\
\hline Southern Asia & India & 11.3 & 38.5 & 12.8 & 2.6 \\
\hline \multirow{4}{*}{ Asia } & & & & & \\
\hline & $\begin{array}{l}\text { Cambodia } \\
\text { Malaysia }\end{array}$ & $\begin{array}{r}7.2 \\
23.0\end{array}$ & $\begin{array}{l}30.7 \\
11.7\end{array}$ & $\begin{array}{r}20.9 \\
\text { No cases }\end{array}$ & $\begin{array}{l}8.7 \\
1.1\end{array}$ \\
\hline & Philippines & 41.0 & 20.8 & 27.1 & 9.0 \\
\hline & Vietnam & 14.8 & 23.5 & 13.4 & 0.5 \\
\hline \multirow[t]{2}{*}{ Western Asia } & Armenia & 29.1 & 18.7 & 0.0 & 4.7 \\
\hline & Jordan & 38.5 & 14.2 & No cases & 0.7 \\
\hline
\end{tabular}

Source: IPUMS and DHS. 


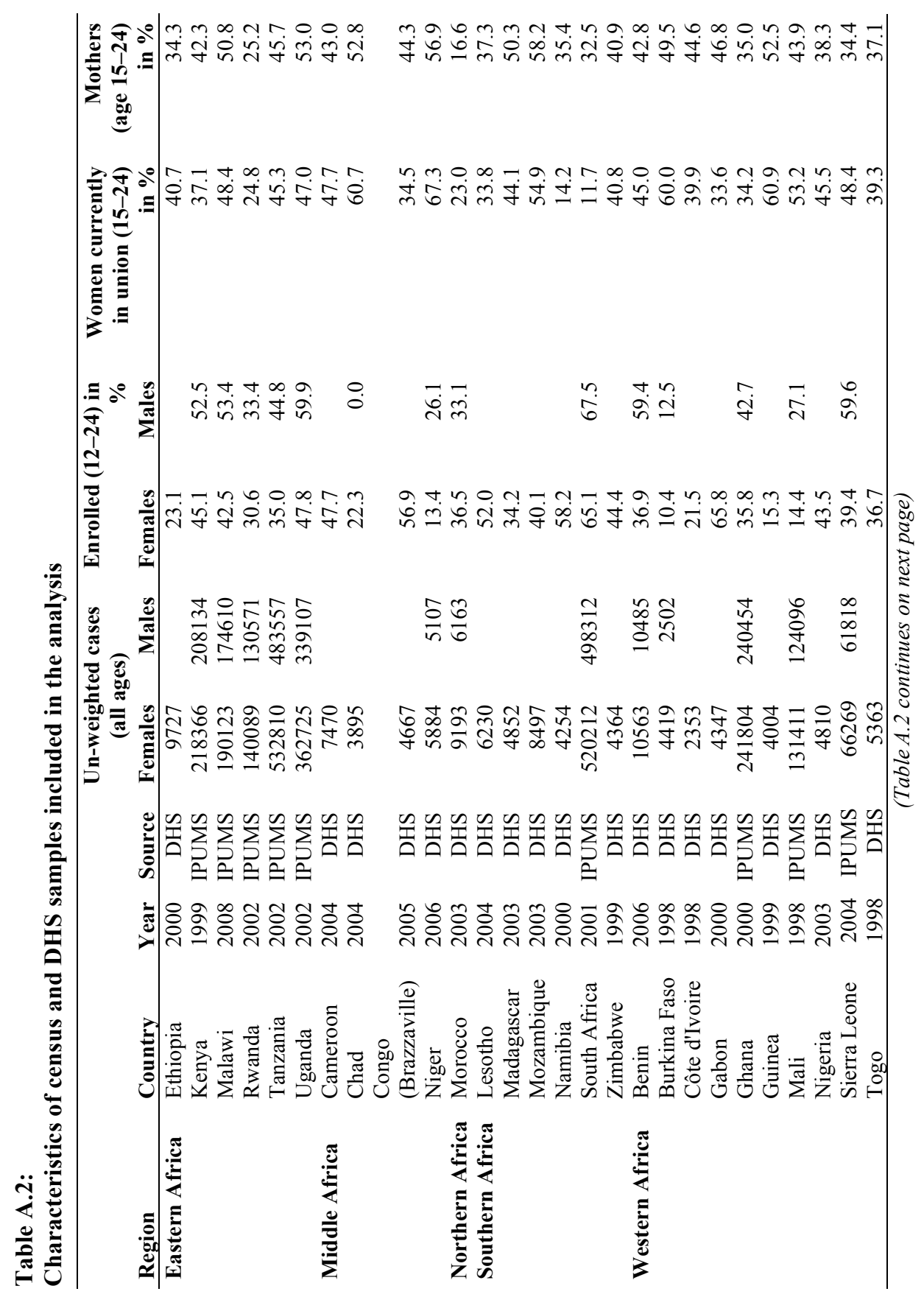






